\title{
STUDI ANALISIS MOTIVASI LULUSAN PENDIDIKAN VOKASIONAL KONSTRUKSI BANGUNAN UNIVERSITAS NEGERI JAKARTA TERHADAP BIDANG KERJA NON-KEPENDIDIKAN (KONSTRUKSI)
}

\author{
Fikri Kurniawan', Rosmawita Saleh ${ }^{2}$, R. Eka Murtinugraba ${ }^{3}$ \\ ${ }^{1}$ Alumni PVKB FT UNJ, fakurtilauz@gmail.com \\ ${ }^{2}$ Dosen PVKB FT UNJ, rosmawitasaleh@unj.ac.id \\ ${ }^{3}$ Dosen PVKB FT UNJ, r ekomn@unj.ac.id
}

\begin{abstract}
Abstrak
Penelitian ini bertujuan untuk memperoleh gambaran motivasi lulusan Pendidikan Vokasional Konstruksi Bangunan FT UNJ terhadap bidang kerja non-kependidikan (konstruksi), penelitian ini dilakukan terihitung dari bulan Juni sampai dengan Juli 2018.

Penelitian dilaksanakan terhadap lulusan Program Studi S1 Pendidikan Vokasional Konstruksi Bangunan FT UNJ, penelitian ini menggunakan metode deskriptif yang bersifat kualitatif, teknik pengambilan data yaitu dengan menyebar angket melalui google form agar lebih mudah mendapatkan jawaban angket.

Hasil yang didapatkan dari penelitian ini yaitu lulusan Pendidikan Vokasional Konstruksi Bangunan memiliki motivasi yang sangat tinggi terhadap bidang kerja nonkependidikan (konstruksi), hal tersebut dibuktikan dengan adanya hasrat dan keinginan (84\%), adanya dorongan dan kebutuhan (83\%), adanya harapan dan cita-cita (85\%), adanya kegiatan yang menarik (84\%), adanya penghargaan $(80 \%)$, adanya lingkungan yang mempengaruhi lulusan untuk bekerja di bidang non-kependidikan (konstruksi) (73\%). Hal tersebut menjadi hasil bahwa lulusan PVKB FT UNJ memiliki motivasi yang sangat tinggi terhadap bidang kerja non-kependidikan (konstruksi).
\end{abstract}

Kata Kunci: Motivasi Lulusan, Bidang Kerja Non-kependidikan

\section{ANALYSIS STUDY ON GRADUATES MOTIVATION OF VOCATIONAL EDUCATION OF BUILDING CONSTRUCTION STATE UNIVERSITY OF JAKARTA TO TH NON-EDUCATIONAL WORK FIELD (CONSTRUCTION)}

\author{
Fikri Kurniawan', Rosmawita Saleb², R. Eka Murtinugraha ${ }^{3}$ \\ ${ }^{1}$ Alumni of PVKB FT UNJ, fakurtilau:@gmail.com \\ ${ }^{2}$ Lecturer of PVKB FT UNJ, rosmawitasaleb@unj.ac.id \\ ${ }^{3}$ Lecturer of PVKB FT UNJ, rekomn@,unj.ac.id
}

\begin{abstract}
This study aims to obtain conception of motivation from graduates of Vocational Education of Building Construction in Faculty of Engineering, State University of Jakarta, to the non-educational work field (construction). It was conducted since Juni to July 2018.

This study was conducted on graduates of bachelor degree of Vocational Education of Building Construction, Faculty of Engineering, State University of Jakarta. It uses descriptive method that is qualitative, the data retrieval technique is done by spreading the quistionnaire via google form to make it easier to get the quistionnaire answer.
\end{abstract}


The result obtained from this study is that graduates of Vocational Education of Building Construction have high motivation to the non-educational work field (construction), they are motivatied by desires and ambitions (84\%), impulses and needs (83\%), hopes and aspirations (85\%), exciting activities (84\%), awards (80\%), environmental influences that affect graduates to work in the non-educational work field (73\%). It becomes the result that graduates of Vocational Education of Building Construction, Faculty of Engineering, State University of Jakarta, have a very high motivation to the non-educational work field (construction).

\section{Keywords: Graduates Motivation, Non-educational work, field}

\section{Pendahuluan}

Perkembangan zaman dan peningkatan daya saing secara global menyebabkan semakin pesatnya kemajuan teknologi yang menuntut sumber daya manusia berkualitas dalam bekerja sesuai dengan bidangnya masing-masing. Sebagai bagian dari sistem pendidikan, Pendidikan Vokasional atau bersifat kejuruan memiliki peran yang sangat penting bagi terwujudnya tenaga kerja yang terampil.

Universitas Negeri Jakarta sebagai salah satu universitas negeri yang ada di Indonesia, memiliki fungsi dalam menghasilkan tenaga akademik dan profesional di bidang kependidikan dan non-kependidikan yang mandiri dan memiliki integritas sesuai dengan tuntutan pembangunan yang berkesinambungan.

Pendidikan Vokasional Konstruksi Bangunan memiliki visi dan misi dalam menghasilkan lulusan, sebagaimana visi dan misi tersebut dijelaskan di dalam buku Pedoman Akademik (2013:309) yang secara garis besar lulusan Pendidikan Vokasional Konstruksi Bangunan cenderung diarahkan untuk bekerja sebagai tenaga pengajar. $\mathrm{Hal}$ ini turut didukung oleh gelar yang disandang seorang lulusan Pendidikan Vokasional Konstruksi Bangunan berupa Sarjana Pendidikan (S. Pd).

Pada kenyataannya, lulusan Program Studi S1 Pendidikan Vokasional Konstruksi Bangunan Universitas Negeri Jakarta yang memiliki gelar Sarjana Pendidikan lebih banyak yang berprofesi sebagai tenaga kerja di bidang konstruksi (non-kependidikan) dibandingkan bidang kependidikan. Hal ini telah dibuktikan dengan adanya penelitian terdahulu yaitu "Analisis Keterserapan Lulusan Program Studi Pendidikan Teknik Bangunan Fakultas Teknik Universitas Negeri Jakarta di Lapangan Pekerjaan" oleh Agustin (2017). Ketidakseimbangan angka jenis profesi menggambarkan bahwa lulusan Program Studi Pendidikan Vokasional Konstruksi Bangunan lebih memilih untuk bekerja bukan sebagai tenaga pengajar (guru).

Motivasi menjadi hal yang penting yang harus dimiliki seorang lulusan Pendidikan Vokasional Konstruksi Bangunan. Motivasi lulusan, baik dari dalam maupun luar, sangatlah berpengaruh dalam memilih bidang profesi yang hendak ditekuni. Sehingga kita perlu megetahui bagaimana motivasi lulusan Pendidikan Vokasional Konstruksi Bangunan dalam memilih bidang kerja non - kependidikan.

\section{Identifikasi Masalah}

Berdasarkan uraian latar belakang yang telah dikemukakan sebelumnya, terdapat beberapa permasalahan yang dapat diidentifikasi sebagai berikut:

1. Bagaimana pandangan lulusan Program Studi Pendidikan Vokasional Konstruksi Bangunan terhadap gelar yang diraih (S. Pd) dalam memilih pekerjaan bidang nonkependidikan (konstruksi)?

2. Mengapa banyak dari lulusan Program Studi Pendidikan Vokasional Konstruksi Bangunan lebih memilih bekerja di bidang non-kependidikan (konstruksi)? 
3. Apakah yang menjadi motivasi dari lulusan Pendidikan Vokasional Konstruksi Bangunan dalam memilih bidang kerja nonkependidikan (konstruksi)?

4. Bagaimana motivasi lulusan Pendidikan Vokasional Konstruksi Bangunan dalam memilih bidang kerja non-kependidikan (konstruksi)?

\section{Pembatasan Masalah}

Menurut identifikasi masalah di atas dan agar pokok bahasan tidak melebar dan menyimpang dari topik utamanya, maka dalam penyusunan skripsi ini, lingkup pembahasannya meliputi:

1. Objek penelitian adalah lulusan Program Studi S1 Pendidikan Vokasional Konstruksi Bangunan Universitas Negeri Jakarta yang terdaftar dalam tahun lulusan 2013 sampai 2018 yang bekerja di bidang nonkependidikan, bidang kerja nonkependidikan khususnya bidang kerja konstruksi.

\section{Rumusan Masalah}

Berdasarkan identifikasi masalah dan pembatasan masalah, maka masalah dapat dirumuskan sebagai berikut: Bagaimanakah Motivasi Lulusan Pendidikan Vokasional Konstruksi Bangunan Universitas Negeri Jakarta terhadap bidang Kerja Non-kependidikan.

\section{Kegunaan Hasil Penelitian}

Penelitian ini diharapkan dapat memberikan manfaat sebagai berikut:

1. Dapat membantu penelitian berikutnya yang relevan dengan penelitian ini.

2. Sebagai bahan masukan bagi Prodi Pendidikan Vokasional Konstruksi Bangunan dalam mengembangkan visi dan misi Pendidikan vokasional Konstruksi Bangunan terhadap dunia kerja.

3. Sebagai bahan masukan bagi dosen dalam mengembangkan proses belajar mengajar di Universitas Negeri Jakarta khususnya Prodi Pendidikan Vokasional Konstruksi Bangunan agar mendapatkan lulusan yang berkompetensi.

\section{Kegunaan Teoretis}

Sebagai bahan masukan bagi dosen dalam mengembangkan proses belajar mengajar di Universitas Negeri Jakarta khususnya Prodi Pendidikan Vokasional Konstruksi Bangunan agar mendapatkan lulusan yang berkompetensi sesuai dengan visi dan misi.

\section{Kegunaan Praktis}

1. Memberikan informasi tentang bagaimana motivasi lulusan Pendidikan Vokasional Konstruksi Bnagunan dalammemilih bidang erja nonkependidikan.

2. Sebagai salah satu persyaratan untuk memperoleh gelar sarjana dan bahan referensi untuk penelitian selanjutnya.

\section{Tinjauan Pustaka}

\section{Motivasi}

Menurut Wibowo (2012:379), mengatakan bahwa motivasi merupakan dorongan terhadap serangkaian proses yang membangkitkan, mengarahkan dan menjaga perilaku manusia menuju pada pencapaian tujuan.

Ada 2 macam motivasi, yaitu:

\section{a) Motivasi intrinsik}

Merupakan motif-motif yang menjadi aktif atau berfungsinya tidak perlu dirangsang dari luar, karena dalam diri setiap individu sudah ada dorongan untuk melakukan sesuatu.

\section{b) Motivasi ekstrinsik}

Merupakan motif-motif yang aktif atau berfungsinya karena adanya perangsang dari luar. Contohnya: seseorang baru akan belajar ketika besok akan dilaksanakan ujian. Motivasi ekstrinsik ini bersifat sementara, tergantung, dan tidak stabil. 
Sardiman (2014:84), mengungkapkan bahwa ada tiga fungsi motivasi yaitu:

1. Mendorong manusia untuk berbuat baik, yakni sebagai penggerak atau motor yang melepaskan energi.

2. Menentukan arah perubahan, yakni ke arah tujuan yang hendak dicapai.

3. Menyeleksi perbuatan, yakni perbuatan-perbuatan apa yang harus dikerjakan yang serasi guna mencapai tujuan, dengan menyisihkan perbuatanperbuatan yang tidak bermanfaat bagi tujuan tersebut.

Menurut Hamzah (2011:23), mengemukakkan indikator motivasi yang dapat diklasifikasikan sebagai berikut: (1) adanya hasrat dan keinginan melakukan kegiatan; (2) adanya dorongan dan kebutuhan melakukan kegiatan; (3) adanya harapan dan cita-cita; (4) adanya penghargaan dan penghormatan atas diri; (5) adanya lingkungan yang baik; dan (6) adanya kegiatan yang menarik.

\section{Pendidikan Vokasional}

Vokasi merupakan produk atau jasa yang menarik dan merupakan pengalaman diri seseorang yang menyebabkan orang lain bergantung atau membutuhkannya sehingga dipanggil atau diundang untuk mengerjakan sesuatu pekerjaan/job. Sehingga, pendidikan vokasional dapat didefinisikan sebagai pendidikan yang berorientasi pada penerapan ilmu. Istilah pendidikan vokasional lebih tepat digunakan daripada pendidikan vokasi yang selama ini dipakai dalam literatur di Indonesia.

\section{Cakupan Pendidikan Vokasional}

Menurut Sudira (2015), Pendidikan Vokasional sebagai pendidikan untuk dunia kerja memiliki cakupan bidang pendidikan yang sangat luas mulai dari program studi di perguruan tinggi dengan status yang tinggi sampai pendidikan menengah dengan status yang rendah hingga pelatihan-pelatihan singkat kompetensi bekerja. Pendidikan di perguruan tinggi dengan status tinggi seperti pendidikan dokter, pendidikan notaris, pendidikan bisnis, teknik dan sebagainya termasuk dalam cakupan pendidikan vokasional sebagai pendidikan untuk pekerjaan/okupasi.

\section{Program Studi Pendidikan Vokasional Konstruksi Bangunan \\ UNESCO (2015), mendefinisikan} Pendidikan Vokasional sebagai aspek-aspek proses pendidikan yang tidak hanya melibatkan pendidikan umum melainkan meliputi studi teknologi, penguasaan keterampilan praktis, sikap, pemahaman dan pengetahuan yang berkaitan dengan pekerjaan di berbagai sektor kehidupan ekonomi.

Program Studi Pendidikan Teknik Bangunan merupakan salah satu Prodi di Universitas Negeri Jakarta yang mengalami perubahan nama program studi. Berdasarkan Surat Keputusan (SK) Rektor Universitas Negeri Jakarta Nomor: 1714/SP/2017 tentang perubahan nama program studi di lingkungan Universitas Negeri Jakarta (UNJ), yang mana Program Studi Pendidikan Teknik Bangunan mengalami perubahan nama menjadi Program Studi Pendidikan Vokasional Konstruksi Bangunan. Hal tersebut didasari atas nomenklatur dari Keputusan Menteri Riset, Teknologi dan Pendidikan Tinggi No. 257/M/KPT 2017 tentang Nama Program Studi pada Perguruan Tinggi. Sejalan dengan penataan kelembagaan Program Studi di UNJ yang dilakukan dengan standarisasi Pangkalan Data Pendidikan Tinggi (PDDIKTI). Pemutakhiran nama Prodi sangat penting, hal tersebut didasarkan pada dinamika dunia kerja yang dinamis membuat beberapa nama Prodi yang namanya terkesan kadaluarsa namanya harus dimutakhirkan sehingga kedepannya program studi tersebut dapat berkembang sesuai kebutuhan dunia kerja.

\section{Pekerjaan di Bidang Non- kependidikan}

Pekerjaan selain bidang kependidikan untuk para lulusan PVKB banyak di jumpai di daerah yang sedang melakukan pembangunan (proyek), pekerjaan dalam bidang konstruksi sangat banyak dan terbagi 
lagi ke dalam jenis pekerjaannya sebagai berikut:
a) Quality Control
b) Supervisor
c) Quantity Surveyor (QS)

\section{Tujuan Penelitian}

Tujuan dari penelitian ini adalah untuk memperoleh gambaran mengenai motivasi lulusan Pendidikan Vokasional Konstruksi Banguanan terhadap bidang kerja non-kependidikan (konstruksi).

\section{Metode Penelitian}

Penelitian ini dilaksanakan terhadap lulusan yang termasuk ke dalam lulusan tahun 2013 sampai 2018 Program Studi S1 Pendidikan Vokasional Konstruksi Bangunan UNJ yang bekerja di bidang nonkependidikan (konstruksi). waktu penelitian dilaksanakan selama 3 bulan dari tanggal 2 Mei sampai 30 Juli (semester genap tahun akademik 2017/2018).

Metode yang digunakan pada penelitian ini adalah survei yang bersifat deskriptif dengan pendekatan kualitatif. Teknik pengumpulan data yang digunakan dalam penelitian ini adalah dengan cara menyebarkan angket atau kuesioner. Kuesioner adalah sejumlah pertanyaan tertulis yang digunakan untuk memperoleh informasi dari responden. Menurut Sugiyono (2014:142), bahwa metode angket (kuesioner) merupakan teknik pengumpulan data yang dilakukan dengan cara memberikan seperangkat pernyataan secara tertulis kepada responden untuk dijawab.

Penelitian ini dilakukan dengan menggunakan google forms, yang mana link dari google forms dibagikan kepada responden. Pengukuran pada kuisioner menggunakan skala likert dengan lima alternatif jawaban pada pertanyaan sebagai berikut:

Tabel 1. Pernyataan Skala Likert

\begin{tabular}{|c|c|}
\hline Alternatif Jawaban & Pernyataan \\
\hline Sangat Setuju (SS) & 5 \\
\hline Setuju (S) & 4 \\
\hline Ragu - Ragu (RR) & 3 \\
\hline Tidak Setuju (TS) & 2 \\
\hline Sangat Tidak Setuju (STS) & 1 \\
\hline
\end{tabular}

Sumber: Sugiyono, 2014

Teknik analisis data yang digunakan dalam penelitian ini adalah dengan menggunakan teknik statistik deskriptif kulitatif dengan menggunakan survey yang berupa instrumen pada saat pengisian instrumen sebagai penguat dari jawaban instrumen yang menggunakan perhitungan persentase. Banyaknya persentase yang didapat maka dapat ditentukan dengan rumus sebagai berikut:

$$
\text { Persentase jawaban }=\mathrm{F} / \mathrm{N} \times 100 \%
$$

Keterangan:

$\mathrm{F}=$ Skor yang diperoleh

$\mathrm{N}=$ Skor maksimal item pernyataan

Pembagian rentang kategori analisis persentase menurut Arikunto (2013:44) dapat dilihat pada table di bawah ini:

Tabel 2. Kategori Analisis Skor

\begin{tabular}{|c|c|}
\hline Prosentase & Kategori \\
\hline $0 \%-19 \%$ & Sangat Rendah \\
\hline $20 \%-39 \%$ & Rendah \\
\hline $40 \%-59 \%$ & Sedang \\
\hline $60 \%-79 \%$ & Tinggi \\
\hline $80 \%-100 \%$ & Sangat Tinggi \\
\hline
\end{tabular}

Sumber: Arikunto (2013:44)

\section{Pembahasan Hasil Penelitian}

Berdasarkan penelitian yang telah dilakukan, didapatkan hasil yang beragam mengenai motivasi intrinsik lulusan terhadap bidang kerja non-kependidikan (konstruksi) yang dikelompokan menjadi 3 sub indikator, sebagai berikut: 
Tabel 3. Motivasi Intrinsik Lulusan

\begin{tabular}{|c|c|c|c|c|c|c|}
\hline Indikator & Sub Indikator & $\begin{array}{l}\text { Skor } \\
\text { (F) }\end{array}$ & $\begin{array}{c}\text { Skor } \\
\text { Maksimum } \\
(\mathrm{N})\end{array}$ & $\mathrm{F} / \mathrm{N}$ & Persentase & Ket. \\
\hline \multirow{3}{*}{$\begin{array}{l}\text { Motivasi } \\
\text { Intrinsik }\end{array}$} & $\begin{array}{l}\text { - Adanya hasrat dan } \\
\text { keinginan terhadap } \\
\text { bidang kerja non- } \\
\text { kependidikan } \\
\text { (konstruksi) } \\
\end{array}$ & 1812 & 2160 & 0,84 & $84 \%$ & $\begin{array}{l}\text { Sangat } \\
\text { Tinggi }\end{array}$ \\
\hline & $\begin{array}{lr}\text { - Adanya dorongan } \\
\text { dan kebutuhan } \\
\text { terhadap bidang } \\
\text { non-kependidikan } \\
\text { (konstruksi) } \\
\end{array}$ & 1794 & 2160 & 0,83 & $83 \%$ & $\begin{array}{l}\text { Sangat } \\
\text { Tinggi }\end{array}$ \\
\hline & $\begin{array}{l}\text { - Adanya harapan dan } \\
\text { cita-cita masa depan } \\
\text { di bidang kerja non- } \\
\text { kependidikan } \\
\text { (konstruksi) } \\
\end{array}$ & 1835 & 2160 & 0,85 & $85 \%$ & $\begin{array}{l}\text { Sangat } \\
\text { Tinggi }\end{array}$ \\
\hline
\end{tabular}

Sumber: Olahan Data, 2018.

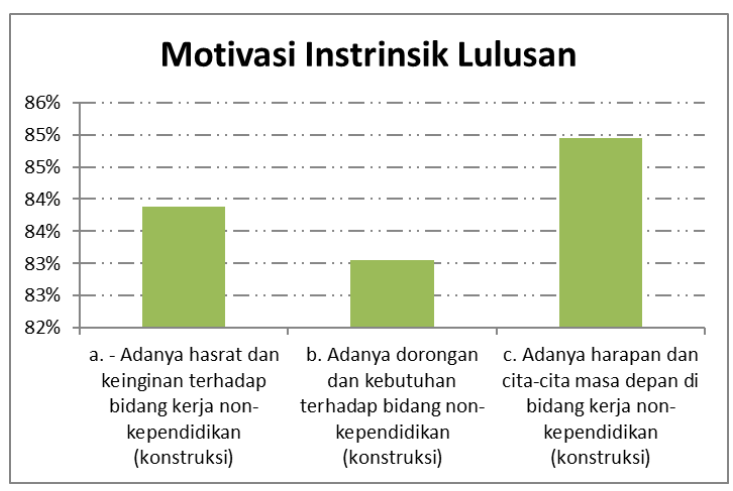

Gambar 1. Diagram Batang Motivasi Intrinsik Lulusan

Berdasarkan data di atas, hasil dari sub indikator adanya hasrat dan keinginan terhadap bidang kerja non-kependidikan (konstruksi) memperoleh nilai yang sangat tinggi, yaitu dengan nilai $84 \%$. Selanjutnya hasil dari sub indikator adanya dorongan dan kebutuhan terhadap bidang nonkependidikan (konstruksi) dikategorikan sangat tinggi yaitu memperoleh nilai $83 \%$. Nilai yang sangat tinggi tersebut juga diperoleh sub indikator adanya harapan dan cita-cita masa depan di bidang kerja nonkependidikan (konstruksi) yaitu dengan nilai $85 \%$. Hasil tersebut menjelaskan bahwa adanya harapan dan cita-cita masa depan sangat mempengaruhi lulusan terhadap bidang kerja non-kependidikan (konstruksi).

Indikator kedua pada penelitian ini menunjukkan tentang dorongan atau rangsangan yang berasal dari luar diri lulusan terhadap bidang kerja nonkependidikan (konstruksi).

Tabel 4. Motivasi Ekstrinsik Lulusan

\begin{tabular}{|c|c|c|c|c|c|c|}
\hline Indikator & Sub Indikator & $\begin{array}{c}\text { Skor } \\
(\mathrm{F})\end{array}$ & $\begin{array}{c}\text { Skor } \\
\text { Maksimum } \\
(\mathrm{N})\end{array}$ & $\mathrm{F} / \mathrm{N}$ & Persentase & Ket. \\
\hline Motivasi \\
Ekstrinsik & $\begin{array}{l}\text { - Adanya kegiatan } \\
\text { yang menarik di } \\
\text { dalam bidang } \\
\text { kerja non- } \\
\text { kependidikan } \\
\text { (konstruksi) }\end{array}$ & 1804 & 2160 & 0,84 & $84 \%$ & $\begin{array}{c}\text { Sangat } \\
\text { Tinggi }\end{array}$ \\
\cline { 2 - 6 } & $\begin{array}{l}\text { - Adanya } \\
\text { penghargaan }\end{array}$ & 1738 & 2160 & 0,80 & $80 \%$ & Sangat \\
\hline
\end{tabular}




\begin{tabular}{|l|l|l|l|l|l|l|}
\hline & $\begin{array}{l}\text { bekerja di } \\
\text { bidang non- } \\
\text { kependidikan } \\
\text { (konstruksi) }\end{array}$ & & & & Tinggi \\
\cline { 2 - 6 } & $\begin{array}{l}\text { - Adanya } \\
\text { lingkungan yang } \\
\text { mempengaruhi } \\
\text { lulusan bekerja } \\
\text { di bidang non- } \\
\text { kependidikan. }\end{array}$ & 1966 & 2700 & 0,73 & $73 \%$ & Tinggi \\
\hline
\end{tabular}

Sumber: Olahan Data, 2018.

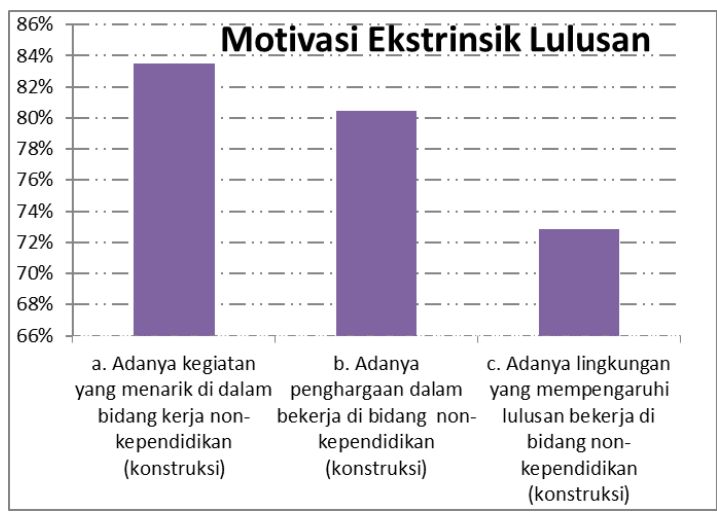

Gambar 2. Diagram Batang Motivasi Ekstrinsik Lulusan

Hasil yang didapatkan menyatakan bahwa $84 \%$ lulusan yang menjadi reponden dalam penelitian ini termotivasi karena adanya kegiatan yang menarik di bidang kerja non-kependidikan (konstruksi). Lulusan menyadari bahwa bekerja di bidang konstruksi dapat menambah ilmu konstruksi dan dapat menemukan hal baru yang mereka tidak dapatkan pada saat perkuliahan. Sub indikator yang berikutnya menunjukkan bahwa $80 \%$ lulusan menjawab bahwa motivasi yang sangat tinggi didapatkan karena adanya penghargaan, penghargaan itu berupa gaji dan promosi jabatan yang didapatkan lulusan pada saat bekerja di bidang nonkependidikan (konstruksi). Motivasi tinggi juga di tunjukan dari adanya lingkungan yang mendorong lulusan untuk bekerja di bidang kerja non-kependidikan, terbukti bahwa $70 \%$ lulusan yang menjadi responden menjawab bahwa lingkungan keluarga dan lingkungan teman merekomendasikan lulusan untuk bekerja di bidang non-kependidikan (konstruksi).

\section{Kesimpulan}

Berdasarkan hasil penelitian dapat disimpulkan bahwa:

1. Setiap lulusan memiliki motivasi yang sangat tinggi dalam memilih bidang kerja non-kependidikan (konstruksi), baik secara intrinsik maupun ekstrinsik.

2. Motivasi seorang lulusan terhadap bidang kerja non-kependidikan (konstruksi) meliputi: Keinginan dan hasrat (84\%); Dorongan dan kebutuhan (83\%); Harapan dan Cita-cita (85\%); Kegiatan yang menarik (84\%); Penghargaan (80\%); Pengaruh lingkungan sekitar $(73 \%)$. Hasil tersebut memiliki angka persentase yang tergolong sangat tinggi yang membuktikan bahwa besarnya motivasi lulusan dalam memilih bidang kerja non-kependidikan (konstruksi). 3. Hal ini turut menunjukan bahwa gelar S. Pd yang diraih oleh seorang lulusan tidak menyurutkan niat mereka dalam memilih bidang kerja non-kependidikan (konstruksi).

\section{Saran}

Berdasarkan hasil penelitian dan kesimpulan di atas, maka dapat disampaikan saran sebagai berikut:

1. Hasil penelitian ini menunjukan bahwa seorang lulusan lebih termotivasi untuk memilih bidang kerja nonkependidikan (konstruksi), sehingga perlu dilakukan penelitan selanjutnya tentang bagaimana membangkitkan motivasi seorang lulusan untuk memilih bidang kerja kependidikan agar sesuai dengan gelar yang didapatkan. 
2. Bagi Program Studi Pendidikan Vokasional Konstruksi Bangunan FT UNJ diharapkan mampu mengubah pandangan mahasiswa melalui pembelajaran lebih intensif mengenai mata kuliah kependidikan, sehingga profesi bidang kerja kependidikan tidak lagi dijadikan opsi ke dua bagi seorang lulusan nantinya.

3. Sebaiknya perlu diadakan kegiatankegiatan untuk lebih mengenal dunia kependidikan, jadi mahasiswa akan termotivasi untuk bekerja di bidang kependidikan dan mencapai kesesuaian visi dan misi dari Program Studi Pendidikan Vokasional Konstruksi Bangunan FT UNJ.

\section{Daftar Pustaka}

Agustin, I.S., Arthur, R., \& Maulana, A. 2017. Analisa Keterserapan Lulusan Program Studi Teknik Bangunan Fakultas Teknik Universitas Negeri Jakarta. Jakarta: Jurnal Pendidikan Teknik Sipil. Vol 6. No.2.

Arikunto, Suharsimi. 2013. Prosedur Penelitian: Suatu Pendekatan Praktik. Jakarta: Rineka Cipta.

Kepmenristekdikti. 2017. Keputusan Mentri Riset, Teknologi, dan Pendidikan Tinggi Republik Indonesia Nomor 257/M/KPT/2017, tentang Nama Program Studi pada Perguruan Tinggi.

Sardiman, A.M. 2014. Interaksi dan Motivasi Mengajar. Jakarta: Rajawali Pers.

Sudira, Putu. 2015. Menegakkan Kembali FT sebagai Fakultas Pencetak Guru Kejuruan Profesional dan Pengembangan Ilmu Pendidikan Vokasional. Yogyakarta: Paper FT UNY.

Sugiyono. 2014. Metode Penelitian Kuantitatif, Kualitatif dan R\&D. Bandung: Afabeta.

UNESCO. 2015. Technical and Vocational Education and Training (TVET). Paris: UNESCO.
Uno, H. Hamzah B. 2011. Teori Motivasi dan Pengukuranya. Jakarta: Bumi Aksara.

Wibowo, 2012. Manajemen Kinerja (Edisi Ke 3). Jakarta: Rajawali Pers. 